\title{
Should We Leave Patients with an Only Hearing Ear to Their Fate?
}

\author{
M. Tayyar Kalcioglu ${ }^{1}$, Serdal Celik ${ }^{1}$, and Fatih Mehmet Hanege ${ }^{2}$ \\ ${ }^{1}$ Department of Otorhinolaryngology, Istanbul Medeniyet University Medical Faculty, Istanbul, \\ ${ }^{2}$ Department of Otorhinolaryngology, Private Giresun Ada Hospital, Giresun, Turkey
}

We have read with great interest the article by Yoo, et al. [1] which presents very important clinical observations. We would like to comment on this article based on our experiences and the literature review.

Surgery for only hearing ear has been avoided since many years as is known. Many authors have not suggested tympanoplasty surgery in an only hearing ear [2]. However, today we have opportunity to add technological developments to the accumulated experience in ear surgery. In our day, quality of life is a very important concern. With better hearing, we can provide better quality of life to the patients. It is not good to leave the patient with tympanic membrane perforation even if it is dry or wet with some hearing loss in this hightech century. Since Cochlear implantation is a treatment option for patients with hearing loss, we should not avoid surgical interventions [3]. Surgery for only hearing ear with cholesteatoma will protect the ear from destructive effects of cholesteatoma and worse hearing level. Tympanoplasty for tympanic membrane perforation without cholesteatoma may provide better hearing or ensure to use hearing aids more effectively. Additionally, during tympanoplasty surgery, some ossicular chain defects, such as incus long process defect may be seen. These kind of problems may deteriorate hearing loss, however, can also be solved by bone cements during surgery

Received June 20, 2016/Revised September 10, 2016

Accepted September 12, 2016

Address for correspondence

M. Tayyar Kalcioglu, MD, Prof.

Department of Otorhinolaryngology, Istanbul Medeniyet University

Medical Faculty, Dr. Erkin Street Istanbul 34722, Turkey

Tel $+905324330695 /$ Fax +902122804007

E-mail mtkalcioglu@hotmail.com

This is an Open Access article distributed under the terms of the Creative Commons Attribution Non-Commercial License (http://creativecommons.org/licenses/by-nc/3.0/) which permits unrestricted non-commercial use, distribution, and reproduction in any medium, provided the original work is properly cited. to improve the quality of life of the patient [4].

In conclusion, we believe that surgery for chronic otitis media with or without cholesteatoma in an only hearing ear should be performed by experienced surgeons. If there is a complication like total hearing loss, we may remember the treatment options, such as Cochclear implantation which protect the patient from deafness.

\section{Conflicts of interest}

The authors have no financial conflicts of interest.

\section{REFERENCES}

1) Yoo MH, Kang BC, Park HJ, Yoon TH. Middle ear surgery in only hearing ears and postoperative hearing rehabilitation. Korean $\mathrm{J}$ Audiol 2014;18:54-7.

2) Battaglia AS, Sabri AN, Jackson CG. Management of chronic otitis media in the only hearing ear. Laryngoscope 2002;112:681-5.

3) Kalcioglu MT, Cetinkaya Z, Toplu Y, Hanege FM, Kokten N. Chronic otitis media surgery in the only hearing ear. B-ENT 2015;11: 223-7.

4) Kalcioglu MT, Tan M, Fleerakkers J. The use of bone cement for ossicular chain defects. Eur Arch Otorhinolaryngol 2013;270:284955 . 